\title{
An update on hemilaminectomy of the cranial thoracic spine: Review of six cases
}

\author{
Kathryn Y. Bray ${ }^{1}$, Peter J. Early ${ }^{2 *}$, Natasha J. Olby ${ }^{2}$ and Melissa J. Lewis ${ }^{3}$ \\ ${ }^{1}$ Carolina Veterinary Specialists, Winston Salem NC 27103, USA \\ ${ }^{2}$ Department of Clinical Sciences, Veterinary Hospital, North Carolina State University, Raleigh NC 27607, USA \\ ${ }^{3}$ Purdue University College of Veterinary Medicine, West Lafayette IN 47907, USA
}

\begin{abstract}
Background: The optimal surgical approach to relieve spinal cord compression in the cranial thoracic spine is not well described, and the anatomy of the cranial thoracic vertebrae creates added surgical difficulty.

Aim: This study describes the surgical approach, treatment, and outcome of three dogs and three cats that underwent a cranial thoracic hemilaminectomy for the treatment of extradural spinal cord compression. Surgical positioning was tailored to avoid extensive dissection and provide for a restricted, careful approach.

Methods: Three dogs and three cats presenting for cranial thoracic spinal cord compression requiring surgical intervention were included.

Results: All patients were discharged within 5 days. No patients experienced postoperative deterioration in neurologic status, and four animals had improved neurologic status at discharge.

Conclusion: In cases with cranial thoracic spinal cord compression, the spinous processes can be spared, extensive muscle dissection minimized, and successful outcomes achieved with the appropriate positioning and limited approach. Keywords: Hemilaminectomy, Intervertebral Disc Disease, Myelopathy, Thoracic.
\end{abstract}

\section{Introduction}

Cranial thoracic compressive spinal lesions are uncommonly reported in veterinary medicine, with the majority of information on intervertebral disc disease in dogs. These cases typically present with clinical signs of T3-L3 myelopathy (trouble walking or moving the hind limbs). Diagnosis of spinal cord disease can sometimes be made with radiographs, myelography, or computed tomography (CT); however, the gold standard for evaluation of the spinal cord is MRI.

The recommended treatment for spinal cord compression, especially causing severe or chronic neurologic signs, is the surgical removal of compressive material. This is accomplished by removing part of the vertebra (laminectomy or hemilaminectomy) to access the spinal canal. However, how to best perform cranial thoracic (T1-T9) spinal surgery is also uncommonly described in veterinary medicine, existing primarily as case reports and small case series (Gilmore, 1983; Liptak et al., 1999; Jäderlund et al., 2002; Gaitero and Añor, 2009; Gaitero et al., 2011). Anatomy of the cranial thoracic spine presents challenges in determining the best surgical approach to address spinal cord disease, since movement around this region is limited by the large muscle mass around the vertebrae (Hansen, 1952; Jeffery, 1995; Wilkens et al., 1996) and the thoracic limbs, scapulae, and musculature interfere with surgical visualization.

The optimal surgical intervention for cranial thoracic spinal cord compression remains unclear. A variety of surgical procedures have been reported in the cranial thoracic spine, including a ventral procedure with surgical division of the sternum (Hearon et al., 2014), partial lateral vertebral body removal (Bottcher et al., 2008), or by removing various portions of the vertebral lamina - described as dorsal, hemidorsal, or modified dorsolateral laminectomies (Parker, 1973; Reidarson et al., 1988; Liptak et al., 1999; Jäderlund et al., 2002; Sumner and Simpson, 2007; Gaitero and Añor, 2009; Hearon et al., 2014). Complications included pneumothorax, rib luxation, subluxation of the spinal column, and immediate post-operative deterioration (Wilkens et al., 1996; Bottcher et al., 2008; Gaitero and Añor, 2009; Hearon et al., 2014).

These previously reported surgical techniques have been associated with difficulty positioning the patient for surgery, limited visualization of the surgical site, the need to remove a large amount of thoracic epaxial muscle, and possible spinal destabilization following such as removal of muscle, ligaments (especially the dorsal tendinous raphe and dorsal interspinous ligament), and part of the vertebra, sternum, or ribs. These factors often lead to an increased risk of surgical complications and a slower recovery of neurologic status. The authors perform a hemilaminectomy in the cranial thoracic spine for ventral or lateralizing compressive lesions, with surgical positioning specifically tailored to maximize visualization and avoid removal of adjacent ribs or scapula. 


\section{Materials and Methods}

Three dogs and three cats were included in the study, based on clinical signs of neurologic deficits in the hind limbs, consistent with T3-L3 myelopathy (Table 1). MRI (1.5T Symphony, Siemens Healthcare) was used to confirm the diagnosis and site of spinal cord compression. Sagittal and transverse planes of the thoracic spine, including T2-weighted and T1-weighted pre- and post-contrast (Gadoversetamide, Mallinckrodt Incorporated) administration were acquired. Results of MRI were consistent with spinal cord compression in the cranial thoracic spine in all cases (Fig. 1). Two dogs had severe ventral and lateral spinal cord compression from suspected intervertebral disc protrusion while the third dog had moderate lateral spinal cord compression from an extradural meningioma. All cats also had severe spinal cord compression, with MRI identifying a contrast-enhancing mass, diffuse infiltrative process, and spinal canal stenosis.

All animals were placed in sternal recumbency with the torso elevated above a standard operating table such that the thoracic limbs could be easily placed in an orthostatic position (Fig. 2A). The thoracic limbs were not secured to the surgical table, with the exception of one cat. Elevation was achieved in cats with additional padded material and vacuum-bags, supporting the thorax and abdomen, allowing the thoracic limbs to approach the operating table (Fig. 2B). Dogs were positioned in a trough padded with vacuum-bags, elevated at the cranial end allowing the thoracic limbs to hang just in front of the trough (Fig. 3). The troughs were secured both to the operating table and to the animal with surgical tape. In this manner, the scapulae were naturally lowered and abducted from the thoracic spine.

By modifying the surgical position, we are able to access the surgical site while avoiding both the scapulae and ribs, spare the supporting supraspinous ligament, and reduce muscle dissection to the intervertebral site of interest. This allows for adequate visualization to remove compressive material while minimizing the risk of pneumothorax or structural destabilization.

In five of the six cases, the surgical site was identified by fluoroscopic guidance using a C-arm (SIREMOBIL Compact L, Siemens Healthcare) and spinal needle (Fig. 4A); once the spinal needle was aligned with the

Table 1. Summary of cases included in the study.

\begin{tabular}{|c|c|c|c|c|c|c|c|c|}
\hline Patient & Signalment & $\begin{array}{l}\text { Onset- } \\
\text { duration }\end{array}$ & $\begin{array}{l}\text { Pre op } \\
\text { neurologic } \\
\text { status }\end{array}$ & Diagnosis & $\begin{array}{l}\text { Post op } \\
\text { hospital } \\
\text { stay }\end{array}$ & $\begin{array}{l}\text { Post op } \\
\text { neurologic } \\
\text { status }\end{array}$ & Follow up & Final outcome \\
\hline $\operatorname{Dog} 1$ & $\begin{array}{l}\text { 9-year-old } \\
\text { MC GSD }\end{array}$ & 7 weeks & $\begin{array}{l}\text { Ambulatory } \\
\text { marked } \\
\text { paresis and } \\
\text { ataxia }\end{array}$ & IVDD T3-T4 & 2 days & $\begin{array}{l}\text { Ambulatory } \\
\text { with mild } \\
\text { paresis and } \\
\text { ataxia }\end{array}$ & 6 months & $\begin{array}{l}\text { Ambulatory with } \\
\text { mild paresis, } \\
\text { ataxia }\end{array}$ \\
\hline $\operatorname{Dog} 2$ & $\begin{array}{l}\text { 8.5-year-old } \\
\text { M GSD }\end{array}$ & 6 weeks & $\begin{array}{l}\text { Paraplegia } \\
\text { with } \\
\text { sensation, } \\
\text { bladder } \\
\text { expressed }\end{array}$ & IVDD T2-T3 & 5 days & $\begin{array}{l}\text { Paraplegia } \\
\text { with sensation, } \\
\text { bladder } \\
\text { expressed }\end{array}$ & 1 year & $\begin{array}{l}\text { Ambulatory with } \\
\text { moderate paresis, } \\
\text { ataxia }\end{array}$ \\
\hline $\operatorname{Dog} 3$ & $\begin{array}{l}\text { 9.5-year-old } \\
\text { MC Mixed } \\
\text { breed }\end{array}$ & 1 week & $\begin{array}{l}\text { Non- } \\
\text { ambulatory } \\
\text { with } \\
\text { moderate } \\
\text { paresis }\end{array}$ & $\begin{array}{l}\text { Meningioma } \\
\text { T5-T6 }\end{array}$ & 2 days & $\begin{array}{l}\text { Ambulatory } \\
\text { marked } \\
\text { paresis, ataxia }\end{array}$ & 6 months & $\begin{array}{l}\text { Ambulatory mild } \\
\text { paresis, ataxia }\end{array}$ \\
\hline Cat 1 & $\begin{array}{l}\text { 9-year-old } \\
\text { MC DSH }\end{array}$ & 1 week & $\begin{array}{l}\text { Ambulatory } \\
\text { with } \\
\text { moderate } \\
\text { paresis, } \\
\text { ataxia }\end{array}$ & $\begin{array}{l}\text { Fibrosarcoma } \\
\text { T2-T3 }\end{array}$ & 2 days & $\begin{array}{l}\text { Ambulatory } \\
\text { with mild } \\
\text { paresis, ataxia }\end{array}$ & 2 years & $\begin{array}{l}\text { Ambulatory with } \\
\text { minimal ataxia }\end{array}$ \\
\hline Cat 2 & $\begin{array}{l}\text { 13-year-old } \\
\text { MC DSH }\end{array}$ & 1 week & $\begin{array}{l}\text { Paraplegia } \\
\text { absent } \\
\text { sensation }\end{array}$ & $\begin{array}{l}\text { Presumed } \\
\text { neoplasia } \\
\text { T2-T3 }\end{array}$ & 5 days & $\begin{array}{l}\text { Paraplegia, } \\
\text { absent } \\
\text { sensation }\end{array}$ & 6 months & Lost to follow up \\
\hline Cat 3 & $\begin{array}{l}\text { 2-year-old } \\
\text { MC DSH }\end{array}$ & 4 days & $\begin{array}{l}\text { Ambulatory } \\
\text { moderate } \\
\text { tetraparesis }\end{array}$ & $\begin{array}{l}\text { Constrictive } \\
\text { myelopathy } \\
\text { C7-T1 }\end{array}$ & 3 days & $\begin{array}{l}\text { Ambulatory } \\
\text { moderate } \\
\text { tetraparesis }\end{array}$ & 3 months & Normal \\
\hline
\end{tabular}

(GSD): German shepherd dog; (DSH): domestic shorthaired cat; (MC): male castrated; (C): cervical vertebra; (T): thoracic vertebra; (IVDD): Intervertebral disc disease. 

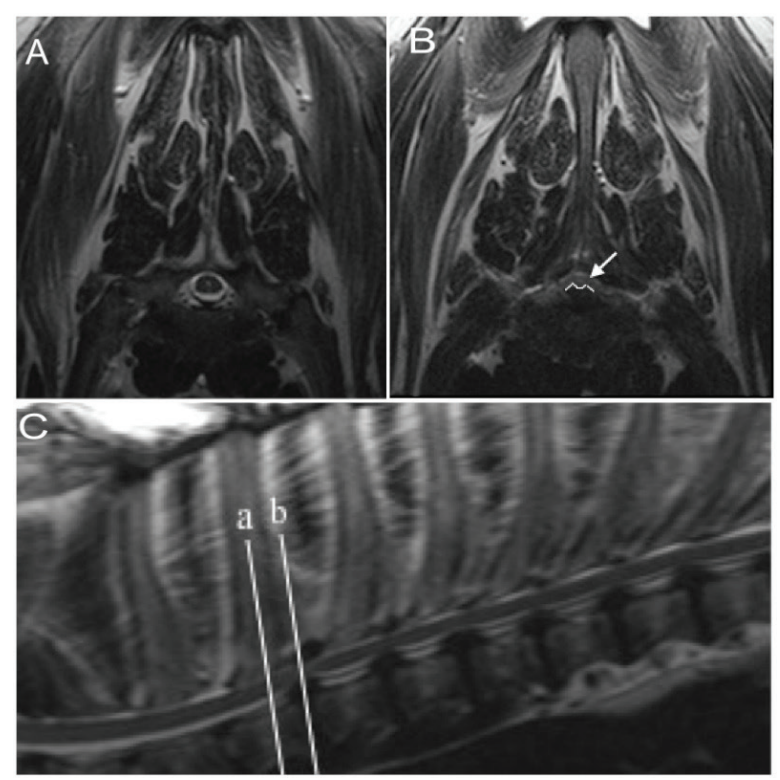

Fig. 1. (A) Transverse T2-weighted image corresponding to white line a. This is a normal cross section of the spine and spinal cord. (B) Transverse T2-weighted image corresponding to white line $\mathrm{b}$. There is a ventral protrusion of the intervertebral disc, outlined in white, causing moderate spinal cord compression (white arrow). (C) Sagittal T2weighted image with white reference lines at mid-body T2 and the T2-T3 intervertebral disc space. Multi-level intervertebral disc dehydration and mild ventral protrusion from T3-4 to T7-8 is also evident.

spinous process of interest, the stylet was removed and the needle cut at the level of the skin with a pin cutter and a final sterile prep performed. The placement of the spinal needle to identify the surgical site allowed the most minimal approach to be made, which further spared extensive muscle dissection. In one case, the surgical site was identified by palpation of the T1 spinous process.

After standard draping, the skin was covered with an additional antibiotic drape. Approach and exposure of the vertebrae was similar to a standard thoracolumbar hemilaminectomy described by Sharp and Wheeler (2005), performed by removing the muscle and its insertions/tendons from the vertebrae of interest as well as one to two vertebra cranial and caudal, followed by bony removal of the facet joint between vertebrae and ultimately removing the side of the vertebra along the area of spinal cord compression (typically creating an elongated rectangular defect in the cranial and caudal aspect of the vertebral bodies). By following the previously placed spinal needle, we minimized dissection of the surrounding muscle and its insertions solely to the vertebrae of interest. The subcutaneous tissues were retracted to reveal the thoracic fascia, which was incised in a paramedian fashion on the side of the lesion to avoid damage to the supraspinous ligament. Exposure of the vertebrae of interest was achieved by
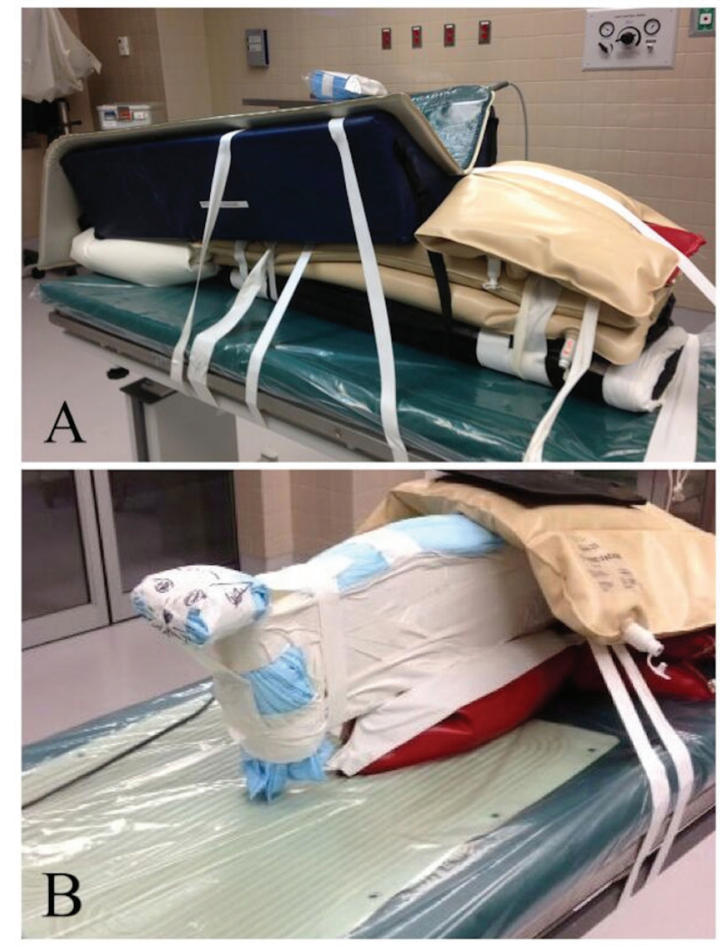

Fig. 2. (A) Surgical table prepared with padded trough and vacuum-bags for positioning of Dog 2, with the head facing to the right of the image. (B) Positioning of Cat 1 using a rectangular box covered with padding, with the head facing to the left of the image.

elevation of the transversospinalis and longissimus muscles from the spinous process, vertebral arch, and transverse and mamillary process, exposing the intervertebral foramen (Fig. 4B). Muscle retraction was maintained with Gelpi (Integra) retractors, and bleeding was controlled with bipolar electrocautery.

A 3-5 $\mathrm{mm}$ pilot hole was created, preferentially in the lamina of the caudal vertebra of interest, using a pneumatic drill (Hall Surgairtome Two, West Coast Medical Equipment) with a round burr in order to identify the orientation of the spinal cord prior to continuing the hemilaminectomy (Fig. 4C). The hemilaminectomy could then be shaped on a case-bycase basis to provide ideal visualization of spinal cord compression, incorporating the pilot hole depending on its initial accuracy (Fig. 4D). This technique is further illustrated in Figures 5 and 6 . There is a minimal associated risk, and the pilot hole allows the surgeon to tailor the hemilaminectomy window appropriately to maximize the removal of compressive material while minimizing trauma to the venous sinus, spinal cord, and ventral nerve root. This also guides the surgeon in removing a portion of the caudal aspect of the transverse process, which facilitates additional visualization and removal of compressive material.

Drilling was continued to contour the hemilaminectomy window based on the extent of spinal cord compression, 

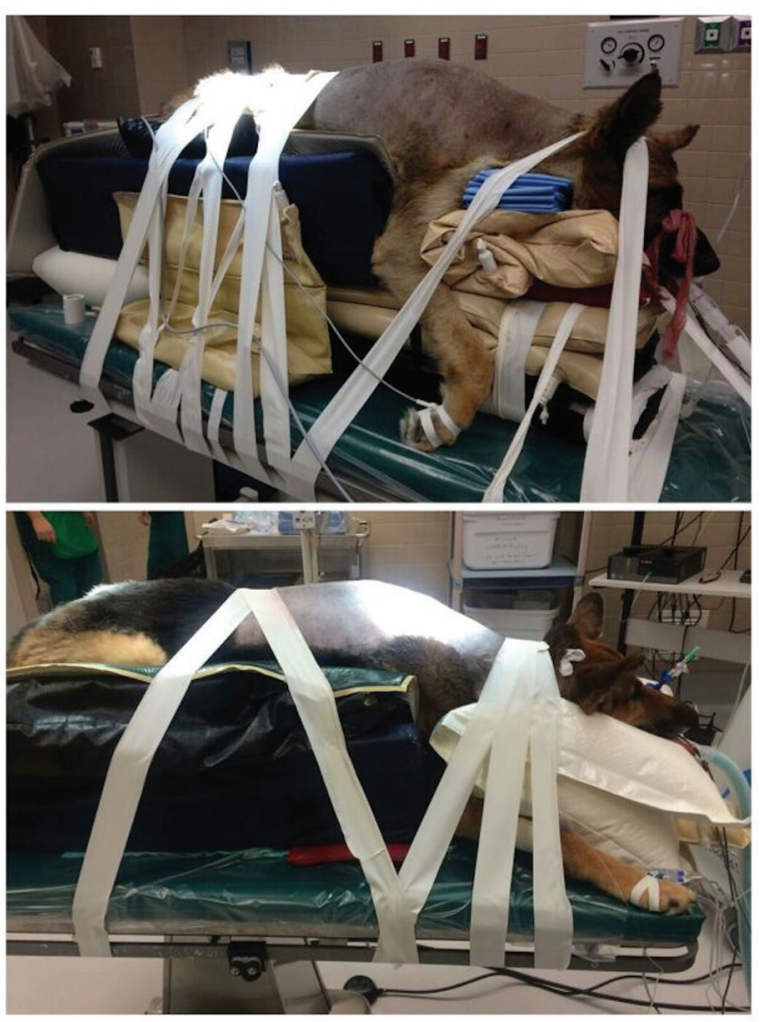

Fig. 3. Surgical positioning of two different canine patients with torsos elevated for thoracic limb arrangement.
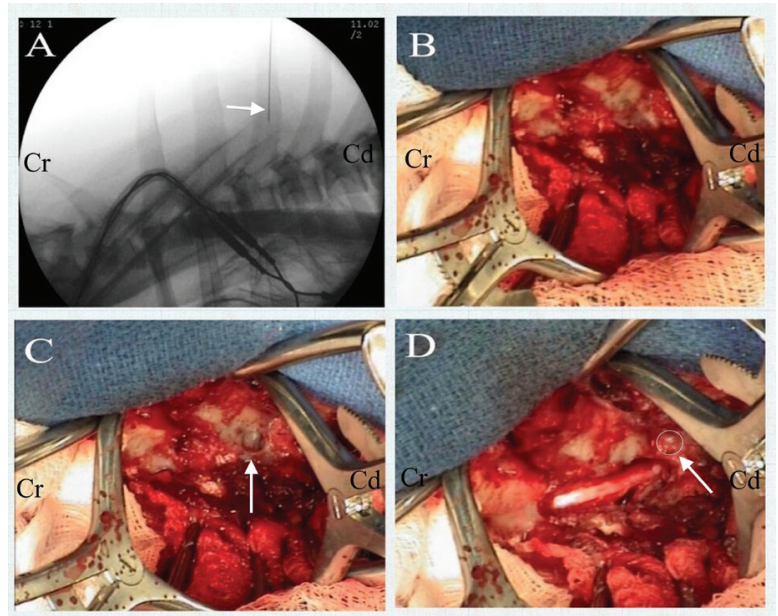

Fig. 4. View from the left side of midline with the head to the left of the picture. Cr indicates the cranial portion of the patient and the caudal portion of the patient is indicated by Cd. (A) Identification of surgical site using a spinal needle (arrow) and fluoroscopic guidance at T3 in Dog 1. (B) Dissection to expose T3 and T4 of Dog 1. (C) Pilot hole (arrow) created in caudal aspect of T4 of Dog 1. (D) Hemilaminectomy at T3-T4 of Dog 1. The pilot hole can be seen caudodorsal to the hemilaminectomy (outlined with a circle), illustrating the use of the pilot hole as a guide for the ultimate ideal placement of the hemilaminectomy.
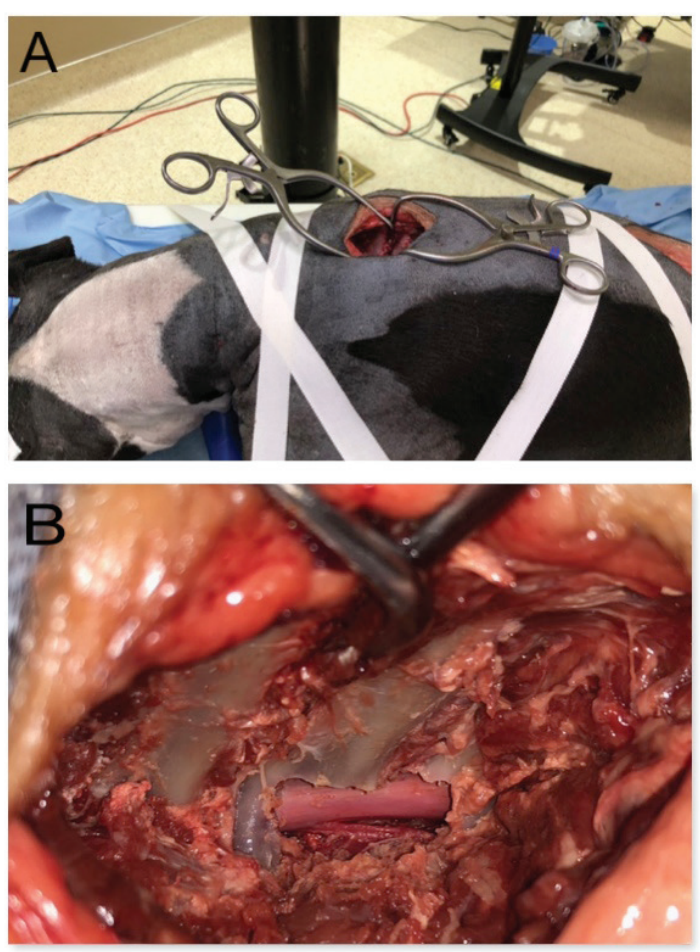

Fig. 5. View of a cadaver dog showing minimal muscle dissection with exposure of spinous processes (A) as well as completed hemilaminectomy (B).

extending if needed over the lamina cranial and caudal relative to the intervertebral disc space. The periosteum was sharply incised and removed, along with regional epidural fat. The extradural spinal cord compression was removed from the vertebral canal. A 2-mm-thick piece of Gelfoam (Pfizer Incorporated) was placed over the laminectomy defect. The thoracic fascia, subcutaneous tissues, and skin were closed routinely. The six animals included in this study were clientowned patients of a tertiary specialty referral hospital, not experimental subjects. As such, an IACUC protocol was not necessary; however, the appropriate standard of care for intra-operative and post-operative analgesia was adhered to with a stringent emphasis on patient comfort.

\section{Results and Discussion}

In the cases of this series, the surgical positioning allowed for a restricted, careful approach without the need for additional incision of the dorsal interspinous ligament or tendinous raphe, retraction of the scapula, or luxation/resection of rib heads. Despite a limited muscular dissection, the approach still provided excellent visualization of the dorsal, lateral, and ventral vertebral canal. By beginning the hemilaminectomy with a pilot hole, spinal cord orientation was easily 


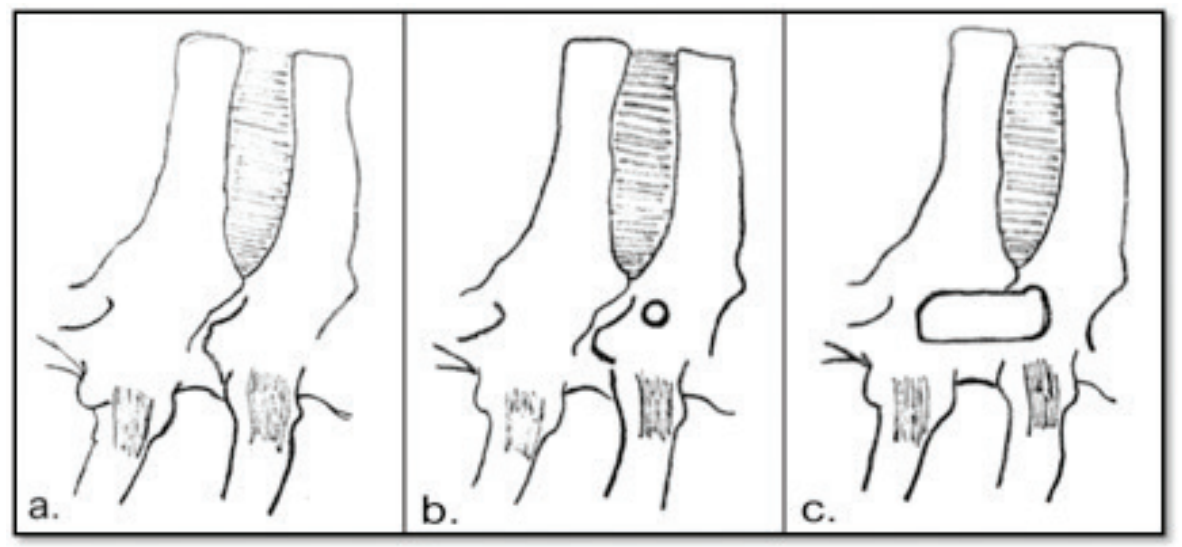

Fig. 6. Illustration of lateral thoracic spine (a) normal, (b) with pilot hole in caudal vertebra of interest, and (c) with hemilaminectomy performed.

assessed to guide further drilling. No intraoperative complications were experienced (i.e., pneumothorax). Postoperatively, each patient was evaluated by neurologic examination every morning of hospitalization. No neurologic deterioration (worsened ability to walk or move the hind limbs) was observed in any of the cases. Hospitalization from surgery to discharge ranged from 2 to 5 days, with the majority of patients leaving the hospital within 3 days after surgery. The longer hospitalization (5 days) occurred in Dog 2 and Cat 2, both paraplegic at the time of surgery. Daily post-operative evaluation during hospitalization demonstrated one case improved from non-ambulatory to ambulatory, two cases remained ambulatory with increased hind limb strength, and three cases were unchanged. Long-term follow-up (Table 1) revealed four cases were ambulatory with paraparesis and one case was normal. The case (Cat 2) that was initially paraplegic with absent sensation was lost to follow up.

Our strategic positioning and approach were feasible in dogs and cats of varying size; body weight in the patients of this report ranged from 3.8 to $36.6 \mathrm{~kg}$. With the described positioning and surgical approach, we were able to completely remove the compressive pathologic material, whether disc or tumor, in all but one patient. None of the cases experienced immediate post-operative deterioration, which has been a concern in many of the previous reports of cranial thoracic surgery in cats and dogs (Sumner and Simpson, 2007; Bottcher et al., 2008; Gaitero and Añor, 2009; Hearon et al., 2014). Hospitalization time was positively impacted by the lack of postoperative neurologic deterioration as well as lack of postoperative complications. Longterm follow-up revealed all dogs and two cats were ambulatory.

Compared with the reported surgical techniques to address cranial thoracic compressive spinal lesions in dogs and cats, one of the main advantages of the hemilaminectomy technique reviewed here includes a less extensive and invasive approach to the vertebrae, thus preserving the supporting ligaments, muscles, and bones such as ribs to maintain vertebral column stability (Parker, 1973; Liptak et al., 1999; Jäderlund et al., 2002; Gaitero and Añor, 2009; Hearon et al., 2014). In addition, this approach may reduce complications such as pneumothorax and may improve postoperative recovery and time to discharge.

The limitations of this study include its retrospective nature and the small number of cases. Both retrospective and additional prospective studies are therefore needed to confirm the efficacy and value of the surgical technique described here. Post-operative imaging would also be useful to demonstrate the extent of decompression and position of hemilaminectomy defect. The majority of animals were ambulatory prior to surgery, which may have made them better candidates for surgery regardless of technique, and lessened postoperative morbidity.

\section{Acknowledgments}

The authors would like to thank Aude Castel, Andrea Tomas, and Tom Jukier for assistance with case collection. The authors would also like to thank John Ladner and Kurt Blackmon for their help in acquiring intraoperative images for this paper. No funding sources were used to support this study.

\section{Conflict of interest}

The authors declare no conflict of interest related to this report.

\section{Authors contribution}

The study was conceived by K.Y.B. and P.J.E. The surgical procedure described was performed by K.Y.B., P.J.E., N.J.O., and M.J.L. The article was written by KYB and PJE. The article was edited and content enhanced by N.J.O. and M.J.L. 


\section{References}

Bottcher, P., Flegel, T., Bottcher, I., Grevel, V. and Oechtering, G. 2008. Partial lateral corpectomy for ventral extradural thoracic spinal cord compression in a cat. J. Fel. Med. Surg. 10, 291-295.

Gaitero, L. and Añor, S. 2009. Cranial thoracic disc protrusions in three German Shepherd dogs. Vet. J. 182, 349-351.

Gaitero, L., Daniel, R., Nykamp, S. and Monteith, G. 2011. Cranial thoracic intervertebral disc disease in German shepherd dogs: a retrospective comparative MRI study [abstract]. J. Vet. Int. Med. 25, 730.

Gilmore, D.R. 1983. Cranial thoracic intervertebral disk extrusion in a dog. J. Am. Vet. Med. Assoc. $182,620-621$.

Hansen, H.J. 1952. A pathologic-anatomical study on disc degeneration in dog, with special reference to the so-called enchondrosis intervertebralis. Acta Orthop. Scand. Suppl. 11, 1-117.

Hearon, K., Berg, J.M., Bonczynski, J.J., Suarez, C. and Bergman, P. 2014. Upper Thoracic Disc Disease (T1-T9) in Large-Breed Dogs. J. Am. Anim. Hosp. Assoc. 50, 105-111.

Jäderlund, K.J., Hansson, K., Lindberg, R. and Narfstrom, K. 2002. T3-T4 disc herniation in a German shepherd dog. Vet. Rec. 151, 769-770.
Jeffery, N.D. 1995. Handbook of small animal spinal surgery, 1st ed. Philadelphia, PA, pp: 9-23.

Liptak, J.M., Watt, P.R., Thomson, M.J., Copeland, S.E. and Galloway, A.M. 1999. Hansen type I disk disease at T1-2 in a dachshund. Aust. Vet. J. 77, $156-159$.

Parker, A.J. 1973. Surgical approach to the cervicothoracic junction. J. Am. Anim. Hosp. Assoc. 9, 374-377.

Reidarson, T.H., Metz, A.L. and Hardy, R.M. 1988. Thoracic vertebral osteochondroma in a cat. J. Am. Vet. Med. Assoc. 192, 1102-1104.

Sharp, N. and Wheeler, S. 2005. Thoracolumbar disc disease. In Small animal spinal disorders: diagnosis and surgery, 2nd ed. Philadelphia, PA: Elsevier Mosby, pp: 121-159.

Sumner, J.P. and Simpson, D.J. 2007. Surgical management of a recurrent spinal meningioma in a cat. Aust. Vet. J. 85, 276-280.

Wilkens, B.E., Selcer, R., Adams, W.H. and Thomas, W.B. 1996. T9-T10 Intervertebral disc herniation in three dogs. Vet. Comp. Orthop. Traumatol. 9, 177-178. 